\title{
Nepal's Health Facility Operation and Management Committees: exploring community participation and influence in the Dang district's primary care clinics
}

\author{
Gagan Gurung ${ }^{1}$, Sarah Derrett ${ }^{2}$, Philip C. Hill ${ }^{3}$ and Robin Gauld ${ }^{4}$ \\ ${ }^{1}$ Postdoctoral Fellow, Department of Preventive and Social Medicine, Dunedin School of Medicine, University of Otago, \\ Dunedin, New Zealand \\ ${ }^{2}$ Professor, Director, Injury Prevention Unit, Department of Preventive and Social Medicine, Dunedin School of \\ Medicine, University of Otago, Dunedin, New Zealand \\ ${ }^{3}$ Professor, Co-Director, Centre for International Health, Department of Preventive and Social Medicine, Dunedin \\ School of Medicine, University of Otago, Dunedin, New Zealand \\ ${ }^{4}$ Professor, Pro-Vice-Chancellor \& Dean, Otago Business School and Division of Commerce, University of Otago, \\ Dunedin, New Zealand
}

\begin{abstract}
Aim: To describe community representation in Nepal's Health Facility Operation and Management Committees (HFMCs) and the degree of influence of community representatives in the HFMC decision-making processes. Background: Community participation has been recognised as one of the key components for the successful implementation of primary health care (PHC) strategies, following the 1978 Declaration of Alma-Ata. In low- and middle-income countries (LMICs), HFMCs are now widely considered as a mechanism to increase community participation in health through community representation. There is some research examining the implementation process, impact and factors affecting the effectiveness of HFMCs. Despite the documented evidence of the importance of factors such as adequate representation, links with wider community, and decision-making power, there is limited evidence about the nature of community representation and degree of decision making within HFMCs in the PHC setting, particularly in LMICs. Methods: Qualitative interviews with 39 key informants were held to explore different aspects of community representation in HFMCs, and the influence of the HFMC on health facility decision-making processes. In addition, a facility audit at 22 facilities and review of HFMC meeting minutes at six health facilities were conducted. Findings: There were Dalit (a marginalised caste) and Janajati (an ethnic group) representations in $77 \%$ and $100 \%$ of the committees, respectively. Likewise, there were at least two female members in each committee. However, the HFMC member selection process and decision making within the committees were influenced by powerful elites. The degree of participation through HFMCs appeared to be at the 'Manipulation' and 'Informing' stage of Arnstein's ladder of participation. In conclusion, despite representation of the community on HFMCs, the depth of participation seems low. There is a need to ensure a democratic selection process of committee members; and to expand the depth of participation.
\end{abstract}

Key words: community representation; degree of participation; Health Facility Operation and Management Committee; health sector decentralisation; Nepal; participation; primary health care

Received 27 April 2017; revised 21 September 2017; accepted 28 December 2017; first published online 28 January 2018

Correspondence to: Dr. Gagan Gurung, Department of Preventive and Social Medicine, Dunedin School of Medicine, University of Otago, PO Box 56 Dunedin 9054 New Zealand. Email: gagan.gurung@otago.ac.nz 


\section{Introduction}

Community participation has been recognised as one of the key components for the successful implementation of primary health care (PHC) strategies following the 1978 Declaration of Alma-Ata (World Health Organization, 1978; Draper et al., 2010), and the concept has become part of policy rhetoric in both high- and lowincome countries (LMICs) (Eyre and Gauld, 2003). There are various arguments in favour of assumed benefits of community participation: cost-effectiveness, acceptability, self-reliance, improved health outcomes, increased legitimacy, and accountability of health-care services (Serapioni and Duxbury, 2014; Bath and Wakerman, 2015). Despite the wider acceptance of the concept, there is a challenge to transform rhetoric into reality (Eyre and Gauld, 2003). The degree of participation within communities is often discussed in the literature, with disagreement about whether a participation activity offers true participation or mere tokenism (Gregory, 2006).

Arnstein's ladder of participation (Arnstein, 1969 ) is among the most popular models, ranking different degrees of participation and conceptualising participation as being about power and powersharing (Coney, 2004; Gregory, 2006). The model is a ladder of 'Eight Rungs' with ascending degrees of participation (Arnstein, 1969). The first two rungs, 'Manipulation' and 'Therapy', are considered nonparticipation as they relate to persuading citizens to follow existing plans and diverting citizens from important issues (Arnstein, 1969). The next set of rungs are 'Informing', 'Consulting', and 'Placation', and represent tokenistic forms of participation (Arnstein, 1969). The higher rungs are 'Partnership', 'Delegated Power' and 'Citizen Control', which are intended to represent true participation (Arnstein, 1969). For Arnstein, participation happens only when there is direct democracy, and citizens are given power (Gregory, 2006).

Health Facility Operation and Management Committees (HFMCs) are now widely recognised as a mechanism to increase community participation in health through community representation, particularly in LMICs (Goodman et al., 2011; McCoy et al., 2012). HFMCs are promoted as a strategy for strengthening health systems based on the principle of health sector decentralisation, thereby improving health service provision
(McCoy et al., 2012; Waweru et al., 2013). The structures, selection process, roles and responsibilities, and authorities of health committees vary and are context specific.

PHC is the main component of Nepal's healthcare system (Bentley, 1995) and includes networks of around 4000 peripheral health facilities (sub-health posts, health posts, PHC centres) (Department of Health Services, 2014) across 75 districts. Peripheral health facilities are managed and supported by the District (Public) Health Offices (Gurung et al., 2015). The PHC system provides basic health services to most of the rural and remote people of Nepal (Bentley, 1995; Karkee and Jha, 2010). Community-based services are provided by female community health volunteers, immunisation clinics, and outreach clinics supervised and managed by PHC centres, health posts, and sub-health posts (Department of Health Services, 2014). All peripheral health facilities have a local HFMC to manage funds, human resources, and health programmes, based on the principle of health sector decentralisation (Gurung and Tuladhar, 2013). HFMCs were introduced to Nepal in 2003 as part of a process of health sector decentralisation (Gurung and Tuladhar, 2013). Each HFMC comprises 9-13 representatives from the village development committee/municipality (Gurung and Tuladhar, 2013). In order to ensure everyone has a voice in the health facility management, a Ministry of Health and Population national guideline directed that membership needs to include the clinic manager, the village development committee chairperson, and elected members including school teachers, female community health volunteers, and at least one of each of the following: Dalit (a marginalised caste), Janajati (an ethnic group), and female representatives (Gurung and Tuladhar, 2013).

The extent to which HFMCs are able to facilitate participation depends on the way members represent their constituents, and their communication with the catchment population (McCoy et al., 2012). The inclusion of community representatives on HFMCs is intended to ensure that local needs are adequately identified, voiced, and addressed (Waweru et al., 2013). Furthermore, as the structure of an HFMC is heterogeneous, with participation involving community members from different backgrounds and service providers, another important aspect in HFMC participation is 
the degree/depth of influence of community representatives. Hence, this study defined participation in this context as the nature of community representation in the HFMC, communication between HFMC members and the rest of the community, and the depth/degree of decision making within the HFMC.

There has been research examining the implementation process, impact, and factors affecting the effectiveness of HFMCs (Molyneux et al., 2012). Despite the documented evidence of the importance of factors such as adequate representation, links with wider community and decision-making power, there is limited evidence about the nature of community representation and degree of decision making within HFMCs in the PHC setting, particularly in LMICs. The aims of this study, therefore, were to: (1) describe community representation in Nepal's HFMCs located in PHC settings; (2) describe communication between HFMCs and their wider communities; and (3) describe the degree/depth of influence of community representatives in the HFMC decisionmaking process.

\section{Dang District context and data collection methods}

This study was part of a broader mixed-methods study conducted in 2014-2015 in the Dang District of Nepal, which is $280 \mathrm{~km}$ west of Nepal's capital city - Kathmandu (Gurung et al., 2017). This article reports findings from the qualitative components. The district has a diverse topography (hill and plain) and ethnic composition with an estimated population of 552583 (Gurung et al., 2017). The Hill Brahmin/Chhetri caste group (upper caste) are the greatest proportion (35\%), followed by Tharu (a Terai Janajati/ethnic group) (30\%) and Magar (a Hill Janajati/ethnic group) (14\%) (District Development Committee, 2014; United Nations Development Programme, 2014). Dalit (a marginalised caste) accounts for $11 \%$ and Yadav (Terai caste) accounts for $1.5 \%$ (District Development Committee, 2014). Nearly $80 \%$ of the people in the Dang live rurally, and two thirds are dependent on agriculture for their livelihoods (Gurung et al., 2017). The Dang District health system includes networks of 39 PHC health facilities, including 21 sub-health posts, 15 health posts, and three PHC centres, governed by the District Public Health Office (Gurung et al., 2017).

Individual qualitative interviews were conducted with 39 participants (HFMC members, service providers, district-level health managers and non-government organisation members) using open-ended interviewing techniques. An interview guide included a list of topics and questions, and included broad questions related to representation in HFMCs, the selection process, communication between HFMC members with the rest of the community, and the decision-making process. However, the interview process was flexible, giving participants freedom to discuss topics of relevance to them. The lead author conducted all 39 interviews helped by a research assistant who took notes. HFMC meeting minutes at six health facilities were also reviewed. These six health facilities were among the eight where participants for the qualitative interviews below district level were selected. In addition, a facility audit was also conducted at the 22 health facilities by using a checklist to assess the representation of different community members in HFMCs. The health facilities visited for the audit were the same 22 health facilities participating in the questionnaire survey of the bigger study. All 39 health facilities were stratified by sub-health posts, health posts, and the PHC centres, and then 22 health facilities (nine sub-health posts, 11 health posts, and two PHC centres) were selected randomly.

The qualitative interviews were audio taped, transcribed and managed within NVivo 10 (QSR International Pty Ltd., 2012). The qualitative interview and document data were analysed using a thematic analysis approach (Bryman, 2008). Both open and structured coding processes were followed. All interview transcripts were read for initial impression with notes made as part of the familiarisation process (Gale et al., 2013). Next, initial coding was undertaken scanning a small number of transcripts which assisted in developing a working coding frame (Gale et al., 2013). All the transcripts were then coded, labelling the texts using appropriate codes. While measuring the depth of participation, further analysis was undertaken using Arnstein's Ladder of Participation (1971) to categorise the levels of participation of HFMCs across different domains of participation. The coding process was iterative, with an evolving coding frame with constant comparison 
and contrast among codes, and looking for patterns and higher level themes (Creswell, 2009; Gale et al., 2013). The coded transcripts were summarised in narratives for each theme supported with verbatim quotes (Creswell, 2009). To analyse the HFMC meeting minutes, we used a simple descriptive tabular analysis in Excel to show frequency of monthly meetings and conducted a thematic analysis to identify the issues discussed.

\section{Ethical approval}

The study was approved by the Human Ethics Committee of the University of Otago, and the Nepal Health Research Council. Written informed consent was obtained from all participants involved in the study. In the case of illiterate participants, verbal consent was obtained, and recorded by the interviewer.

\section{Results}

\section{Characteristics of participants}

Of the 39 respondents $($ male $=34$, female $=5)$, the majority were Brahman/Chhetri (an upper caste) $(74 \%)$ followed by Dalit (a marginalised caste) (10\%) and Janajati (an ethnic group) (10\%). Types of participants included: HFMC members (15), service providers (14), and non-government organisation staff/members (10). The HFMC participants included chairs, teachers, social workers, Dalit and female members. The committee members were unpaid volunteers. The role of a HFMC chair was to provide overall leadership of a committee; plan, implement and monitor health services within the catchment area of a health facility; and manage human resources by supervision, sanctioning leave and attendance at training. Other members had responsibilities to actively participate in planning and prioritisation of health services, mobilisation of local resources, and raising issues from the communities they represented. In the case of the service providers, participants were clinic managers and other service providers of the PHC facilities, and the chief and other district-level health workers from the District Public Health Office.

\section{Community representation}

The Ministry of Health and Population national guideline (Guideline for Handover and Operation of Local Health Facility, 2003) developed by the National Health Training Centre, states that each HFMC needs at least one Dalit and one Janajati representative. The health facility audit of 22 HFMCs found that there was Dalit and Janajati representation in $77 \%$ and $100 \%$ of the committees, respectively. Female representation included at least two members in each committee. Similarly, all the committees had at least one teacher and female community health volunteer. However, qualitative interviews revealed that, due to the lack of local body elections, the village development committee secretaries, who are government officials, were acting as chairs of the committees in many health facilities rather than having elected chairs from the village development committees.

\section{The selection of members}

Although it appeared that HFMC representation followed the national guidelines for inclusive representation, in many cases, politics were the driving force behind the committee formation to ensure representation from the main political parties. In some cases, because of political sharing across all the main political parties in HFMCs, representation of Dalit community members was omitted:

\begin{abstract}
We are an 11 member committee but do not have Dalit representation. It is because we tried to have representation from all main political parties. Due to this process the Dalits were left out.
\end{abstract}

(Qualitative interview, HFMC member, PHC centre 2)

Furthermore, very few members of HFMCs were selected by the public. In many of the cases the clinic manager, together with the village development committee secretary, decided who should serve on the committee in consultation with local political party representatives. Hence, in the absence of a locally elected body, bureaucratic officials determined the membership of the HFMCs:

Our committee was formed in such a way that the staff [clinic manager] picked those who were his relatives or who he likes.

(Qualitative interview, Dalit HFMC member, sub-health post 1) 
However, in some health facilities it was found that a public gathering had been called, and members selected democratically.

\section{Communication between HFMCs and the wider community}

The analysis of meeting minutes showed a range of issues discussed in the HFMC meetings: infrastructure and resource mobilisation, human resources (the hiring of local staff, staff motivation, salary and benefits, fulfilment of sanctions, regularity, and behaviour of service providers), service planning and development (provision of additional services such as laboratory services, conducting outreach clinics in remote areas and access to medicines), and health awareness raising. However, interviews revealed that the collection of issues from community constituents was virtually absent as none of the members brought issues from consultation with their respective constituents. This indicates that HFMC members were more likely to be representing their own views, rather than those of their constituents, although some mentioned that they occasionally did so informally, relating to clinic opening hours, lack of availability of medicine in health facilities, and health worker behaviour. Further, there was no practice of providing feedback about responses to the community. Similarly, the HFMC meetings were not open to the public to gather their views. In a few cases, HFMCs invited selected people to meetings to generate support for selected planned activities such as mass awareness campaigns or infrastructure development:

We do not have a regular HFMC meeting. Actually, I feel there is no need for regular meetings. It is because there is no agenda from other committee members. I prepare the agenda and they just accept what I said. They [community representatives] never bring any issues from their village. There are issues in the community, but they do not bring them.

(Qualitative interview, clinic manager, sub-health post 2)

\section{The depth of participation in HFMCs}

In many places, there were no regular monthly meetings of HFMCs. Among the three sampled health facilities whose meeting minutes were reviewed for a three-year period, it was found that no monthly meeting was held in 14 of the 36 months in two health facilities, nor in 18 months in the third health facility. Similarly, in three other health facilities of which meeting minutes were reviewed for a two-year period, it was found that no monthly meeting was held in 8,16 and 17 of the 24 months, respectively. The main reasons for not having regular meetings included: a lack of identified need to meet monthly as they felt there were no issues to discuss, busy schedules of members especially managers and chairpersons; and meetings not being called by the managers who had the secretarial responsibility to call the meetings. When meetings were not held, this significantly reduced the opportunities for the community representatives to take part in decision making.

The study found that meetings were more regular in clinics where the HFMCs were chaired by a community representative, rather than by the village development committee secretary. It appeared that locally selected chairs were more accessible and gave more time to the committees and the health facilities. In contrast, village development committee secretaries generally did not stay in the village, and were busy with other responsibilities:

When the village development committee secretary was the chairperson of the HFMC, it was difficult to organise timely HFMC meetings. It was because he did not stay at village but in the district head quarter, and did not have time for the HFMC meetings. Due to this the committee replaced him with the one selecting from the local community. Since he [present chairperson] is from the local community and can give his time when required, it is easier for the committee and staff to work.

(Qualitative interview, clinic manager, PHC centre 2)

Although it appeared that decisions in the meetings were made by HFMCs, such meetings were led by clinic managers. Furthermore, most of the agendas were prepared by the clinic manager, with little input from the other HFMC members:

The Committee [HFMC] is driven by the clinic manager. On paper, it seems that the decision is made and implemented through the committee [HFMC], but the role played by 
the committee members is insignificant. In short, the main role in decision making is of the clinic manager; but for formality, the signatures [in the meeting minutes] are those of the HFMC.

(Qualitative interview, auxiliary health worker, health post 1)

The clinic manager of one PHC centre mentioned that committee members were from the local community, but they did not come with strong intellectual backgrounds and qualifications, and found it difficult to understand technical matters. Therefore, the agenda in the HFMC meetings was determined by him:

Due to the committee's background and knowledge of technical matters of health, the clinic manager is the one who gives direction to the clinic. Generally, the agenda for meetings [HFMC] is pre-set and determined by myself [clinic manager] and they [HFMC members] simply accept my proposal.

(Qualitative interview, clinic manager, PHC centre 2)

The selection process of HFMCs as mentioned previously also affected the participation process. In situations when members were selected by clinic managers, members could not voice their concerns strongly against service providers:

Who selected the committee? Yes, members are selected as per the decision of the chief [clinic manager]. Those who he likes are selected for the committee. Can such members speak against him? Hence, they remain just silent.

(Qualitative interview, office assistant, sub-health post 1)

There was no meaningful participation of Dalit or females in decision making; lack of empowerment and cultural barriers were identified as the reasons for low level of participation:

The concept of making an inclusive committee by representing marginalised people is ideologically sound. But for such thing to be realised, there is a need for development of capacity and empowerment of members too. For now it remains just a ritual to follow the guideline to include the [marginalised] from all sections. There was no attention on whether he/she is interested to participate or capable to do so. For example I was talking about our Dalit member. If those Dalit settlements internalise that we have a representation in the health committee and he should represent our voice and speak our agenda and rights [in the health system], then such representation may make sense. But in reality they do not know at all about the concept and the member. So it is like if someone come here from above [higher authority] for supervision and monitoring, it would give an impression to him/here that there is an inclusive representation. But it does not have meaning in a real sense.

(Qualitative interview, HFMC chair, PHC centre 2)

A Dalit member shared her experience about how the 'untouchable' issue in the HFMC affected her participation:

In the committee, most of the members are from higher castes. When we have meetings of the committee or any other program, and when there is time for taking snacks, the other committee members sit a short distance away from me. There is thus still discrimination in our society. It [untouchability issue] is not in all places, but still exists with some people in some places. Due to this, it causes me stress inside. Then, how can I speak in the meeting or any events without hesitation?

(Qualitative interview, Dalit HFMC member1, sub-health post 1)

The HFMC role was confined to mobilising additional resources for the clinic, supporting the infrastructure, and raising health awareness. They had some say in recruiting local staff, spending locally mobilised resources, and providing additional services. In the case of hiring local staff, HFMCs and clinic managers jointly discussed and formed recruitment committees at the local level and had key roles in hiring and managing local staff. However, they had very limited decision making power on health needs assessment, planning, staffing, and fund management, due primarily to the lack of health sector decentralisation in the study district. Consequently, with such 
centralised planning, the HFMCs were without authority to manage staff and funds. Clinic managers and the village development committee secretaries were the ones who managed funds coming from the centre. The lack of health sector decentralisation was closely linked to the lack of a locally elected body in the district:

We [HFMC] are playing the role of the helping hand to the health post and staff... . in their direction, we [HFMC] support them by any means, such as managing infrastructures, hiring additional staff, etc.

(Qualitative interview, HFMC chair, health post 3 ).

The entire budget which comes through village development committee and Public Health [District Public Health Office] is known only to the chairperson [village development committee secretary] and clinic manager. They put on the agenda items they think are necessary for the meeting. We, the rest of the members, come into the meeting, write our signatures and walk away. The main driving force is them [the village development committee secretary and clinic manager]. The 'handle' is with them for health facility conduction. We do not have a prominent role.

(Qualitative interview, HFMC member1, sub-health post 1)

This study showed that the depth and scope of participation via Nepal's HFMCs was low. When compared with Arnstein's ladder, participation through HFMCs appeared to be at the 'Manipulation' and 'Informing' stage (Arnstein, 1969). Clinic managers were dominant in selecting committee members and shaping the agenda for
HFMCs. Although it appeared that decision making at the meeting was made by the committee, clinic managers were the ones who dominated, creating a tendency for manipulation. Similarly, HFMC meetings were widely used by clinic managers and other staff to provide key updates about health facility services to committee members. In many cases, HFMCs were only informed in the meeting about expenditure made by the clinic manager and village development committee secretary, and HFMCs approved the expenses to be reported on. The depth of participation varied by the domain of decision making. For example, HFMCs had a higher level of participation in areas such as the hiring of local staff, and managing local resources, but had no role in disciplining permanent health workers or in health needs assessment. In the case of hiring local staff, HFMCs and clinic managers jointly discussed and formed recruitment committees at the local level and hired staff following a procedure where they had the key roles in hiring and managing these local staff. Regarding the domain of decision making (Charles and Demaio, 1993), the HFMC's role was more confined to mobilising additional resources for health facilities, supporting infrastructure, and raising health awareness, but less in health needs assessment, planning, staffing, and funding management (see Table 1).

\section{Discussion}

The study found that while there was representation of females, Dalit and Janajati in HFMCs, there was no democratic selection process and HFMCs were influenced and captured by powerful elites. The problem of representation has also been reported in prior studies conducted in Niger, the Philippines, Kenya (Ramiro et al., 2001;

Table 1 Health Facility Operation and Management Committees' domains and depth of participation (Arnstein, 1969)

\begin{tabular}{lllll}
\hline & & \multicolumn{2}{c}{ Depth of participation } \\
\cline { 2 - 4 } Domains of participation & Manipulation & Informing & Consultation & Partnership \\
\hline Infrastructure & & & Citizen control \\
Local resources & & & \\
Management of local staff & & \\
Management of permanent staff & & \\
Financial management & & \\
Health needs assessment & & \\
\hline
\end{tabular}


Meuwissen, 2002; Sohani, 2005), and other developed countries (Gauld, 2010; Serapioni and Duxbury, 2014). Adequate representation and an appropriate selection process of the HFMC members are key initial steps to determining the functioning of the HFMC, and members' legitimacy (McCoy et al., 2012). Those who are handpicked by clinic managers or political parties are not accountable to the wider community. There is a need to have a democratic selection process of HFMC members, preferably by public gatherings, so that members are accountable to their constituents.

The present study found that, in most cases, HFMC members did not consult with the community in a regular or systematic way, indicating a disconnect between the committee and the broader community. Further, there was no practice of providing feedback to the community. This raises questions as to whether community representatives only put their personal concerns forward, rather than channelling the concerns of the rest of the community. This finding is consistent with past studies conducted in Bangladesh, the Philippines, and African countries, which showed that committees did not reflect the concerns of the population (Mahmud, 2004; Goodman et al., 2011; Falisse et al., 2012). Selection of members by wider public consultation (election or public gathering), together with activities to improve awareness of the HFMC and their roles, would possibly address this gap.

This study showed that the depth of citizen participation via Nepal's HFMCs was low. HFMC roles were confined to helping hands to support clinic managers, but they had no role in disciplining permanent health workers or in health needs assessment. Studies conducted in other Asian and African countries reported that committees had no say in the management of funds, pharmaceuticals or staff, and they had a limited oversight function and role in mobilising local resources and raising awareness (Ramiro et al., 2001; Kapiriri et al., 2003; Loewenson et al., 2004; Uzochukwu et al., 2004; Sohani, 2005; Goodman et al., 2011). There were some inter-related factors affecting the depth of participation.

Following the above, one factor, in the Nepalese context, was the lack of a locally elected body in the study district. During the decade long political conflict which ended in 2008 , there were no local body elections in Nepal. Due to this, there was no elected chair or members to represent the HFMC. Instead, as discussed previously, members were often selected by clinic managers and local political elites. In such situations, certain members could not state their concerns about service providers in the committee. This absence of an elected body also meant that there was a lack of proper health sector decentralisation. As a result, planning was centralised and the HFMCs had limited authority to manage funds and staff. Clinic managers, village development committee secretaries and political party representative were therefore dominant in decision making.

It is worth noting that clinic managers were more powerful than others because they dominated decision making, from selection of members on the committee, to shaping the agenda for the meetings. Hence, there were both power and information asymmetries between clinic managers and other members. Few et al. (2003) in their study in Zambia and Tanzania found that, due to power and information imbalances, service providers controlled the committee, and the committee was seen as a body designed to serve the clinics, rather than the community. Similarly, Loewenson et al. (2004) reported that in Zimbabwe, due to the lack of knowledge of health resources, staffing levels, or budgets, the HFMCs were not able to hold health services accountable.

Another issue in HFMC participation is the participation of marginalised sections of the community on the committee. Although there was representation of Dalit and females on the committee, they had no meaningful participation in decision making. The current provision of a quota system to represent Dalit and females in HFMCs without concurrent empowerment is less likely to challenge the prevailing socio-cultural inequalities. Quotas appeared to create participation space for marginalised groups but, in themselves, do not empower people sufficiently to voice their concerns (Thomas et al., 2003; Goodman et al., 2011). In the Dang district study, there were difficulties for Dalit representatives in participating in the decision-making process of the HFMC because males, higher castes, and more powerful members dominated the process. The ways in which cultural factors affected the participation process are highlighted in many other studies in Africa and Nepal (Sepehri and Pettigrew, 1996; Kapiriri et al., 2003; 
Loewenson et al., 2004). Sepehri and Pettigrew (1996) also highlighted that Nepalese society is characterised by hierarchies - by caste/ethnicity, wealth, gender and power - and these hierarchies prevented health committees from adequately representing the interests of their community. Hence, inequalities apparent in society, of gender, caste, and wealth, were reinforced in the committee structure as Mahmud (2004) also found in Bangladesh. Continued efforts are necessary to empower community members to ensure their participation is more than token (Gurung et al., 2015). For this, appropriate consultation with the marginalised community members and capacity building of their representatives in HFMCs are necessary.

A strength of this study is that, unlike previous studies, we clearly analysed how the Arnstein's ladder of participation varies by different domains of participation. The findings of the study could be a useful resource to develop strategies to increase the depth of participation focusing on the appropriate domains. However, there are a number of new models for participation proposed by different authors (Charles and Demaio, 1993; Canada, 2000; Bishop and Davis, 2002; Tritter and McCallum, 2006; Carman et al., 2013). Recent models move away from ladders, to describe participation as a continuum offering a set of choices rather than citizen control as the only ideal goal of participation (Gregory, 2006). Similarly, there are other useful models measuring different aspects of participation (Rifkin et al., 1988). We chose Arnstein's model to focus on measuring depth of participation in terms of power on the HFMCs. Overall, the study suggests that there is a need to address decision-making power between service providers and the community. The lack of power, the focus only on mobilising additional resources, and the role of 'helping hands' appear to make the HFMCs susceptible to feeling demotivated (McCoy et al., 2012). However, it is very unlikely that the continuum of power would be easily directed towards communities (Arnstein, 1969). Hence, concepts of co-governance (Brinkerhoff, 2011) and partnership approaches with the focus on mutual problem-solving appear more appropriate to help avoid such power struggles (Gurung et al., 2015). There is a need for decentralisation of more authority to Nepal's HFMC members. Many studies have highlighted that decentralisation of power to local levels, combined with community participation, leads to increased responsiveness from service providers to the citizens in LMICs (Ramiro et al., 2001; Iwami and Petchey, 2002; Berlan and Shiffman, 2012). It is important to note that Nepal promulgated a new Constitution on 20 September 2015 that initiated the country's transition to a federal state (Constituent Assembly Secretariat, 2015; Simkhada et al., 2015). Currently, the election of local government is underway (Asia Pacific International Foundation for Electoral Systems, 2017) and there is hope that the newly elected local governments will help revamp the HFMC structure with more power.

This study did have some limitations. For example, only a small number of participants were female. Key positions within the health facilities and HFMCs were held by men. As we selected qualitative interview participants based on the principle of selecting 'information-rich cases' (Patton, 1990) to yield in-depth understanding on the issues under study, it resulted in selection of more male participants. But, whenever possible, female members from HFMCs and service providers were included to ensure 'heterogeneity' (Patton, 1990) and identify divergent perspectives. All the interviews were conducted by a male interviewer, however, every effort was made to facilitate a rapport with female respondents, and to explain the purpose of the research. Women were also encouraged to have someone else sit next to them during the interview process for personal support.

\section{Conclusion}

This study showed that the depth of public participation in Nepal's HFMCs was low. There is a need to ensure a democratic selection process of committee members, and to expand health sector decentralisation. The country's recent transition to a federal state and the current election of local governments is a positive step. Continuous capacity building of community representatives in HFMCs, especially marginalised community members is necessary. There is also a need for orientation of service providers, including clinic managers, about the importance of community voice to strengthen the health system so that they are ready to share power and accommodate community concerns. This study illustrates how 
Arnstein's ladder can be applied through field research in a LMIC context to measure participation in community health-care organisations. The study findings should help strengthen the functioning of Nepal's HFMCs and improve community participation in its $\mathrm{PHC}$ system; the findings may also be applicable to other LMICs with similar contexts.

\section{Acknowledgements}

The authors wish to thank University of Otago, New Zealand who provided funding for the research. They would like to thank Dang District Public Health Office team and study participants of the Dang District, Nepal for their support and co-operation.

\section{Conflicts of Interest}

None of the authors declared any conflicts of interest.

\section{References}

Arnstein, S. R. 1969: A ladder of citizen participation. Journal of the American Institute of Planners 35, 216-24.

Asia Pacific International Foundation for Electoral Systems 2017: Elections in Nepal: 2017 local elections frequenstly asked questions. Arlington, VA: Asia Pacific International Foundation for Electoral Systems.

Bath, J. and Wakerman, J. 2015: Impact of community participation in primary health care: what is the evidence? Australian Journal of Primary Health 21, 2-8.

Bentley, H. 1995: The organisation of health care in Nepal. International Journal of Nursing Studies 32, 260-70.

Berlan, D. and Shiffman, J. 2012: Holding health providers in developing countries accountable to consumers: a synthesis of relevant scholarship. Health Policy \& Planning 27, 271-80.

Bishop, P. and Davis, G. 2002: Mapping public participation in policy choices. Australian Journal of Public Administration $61,14$.

Brinkerhoff, D. W. 2011: Community engagement in facilitybased quality improvement in the Philippines: lessons for service delivery and governance. Bethesda, MD: Health Systems 20/20.

Bryman, A. 2008: Social research methods. New York, NY: Oxford University Press.

Canada, H. 2000: Health Canada policy toolkit for public involvement in decision making. Ottowa, Canada: Health Canada.

Carman, K. L., Dardess, P., Maurer, M., Sofaer, S., Adams, K., Bechtel, C. and Sweeney, J. 2013: Patient and family engagement: a framework for understanding the elements and developing interventions and policies. Health Affairs 32, 223-31.

Charles, C. and Demaio, S. 1993: Lay participation in health care decision making: a conceptual framework. Journal of Health Politics, Policy and Law 18, 881-904.

Coney, S. 2004: Effective consumer voice and participation for New Zealand: a systematic review of the evidence. Wellington, New Zealand: New Zealand Guidelines Group.

Constituent Assembly Secretariat 2015: Constitution of Nepal, 2015 [Online]. Kathmandu, Nepal: Constituent Assembly Secretariat. Retrieved 30 March 2016 from http://www.icnl. org/research/library/files/Nepal/Nepalconst.pdf.

Creswell, J. W. 2009: Research design: qualitative, quantitative, and mixed methods approaches. Los Angeles, CA: Sage.

Department of Health Services 2014: Annual report 2013/14. Kathmandu, Nepal: Government of Nepal, Ministry of Health and Population.

District Development Committee 2014: District profile of Dang 2014: Dang, Nepal: Government of Nepal, Ministry of Federal Affairs and Local Development.

Draper, A. K., Hewitt, G. and Rifkin, S. 2010: Chasing the dragon: developing indicators for the assessment of community participation in health programmes. Social Science \& Medicine 71, 1102-109.

Eyre, R. and Gauld, R. 2003: Community participation in a rural community health trust: the case of Lawrence, New Zealand. Health Promotion International 18, 189-97.

Falisse, J. B., Meessen, B., Ndayishimiye, J. and Bossuyt, $M$. 2012: Community participation and voice mechanisms under performance-based financing schemes in Burundi. Tropical Medicine \& International Health 17, 674-82.

Few, R., Harpham, T. and Atkinson, S. 2003: Urban primary health care in Africa: a comparative analysis of city-wide public sector projects in Lusaka and Dar es Salaam. Health \& Place 9, 45-53.

Gale, N. K., Heath, G., Cameron, E., Rashid, S. and Redwood, S. 2013: Using the framework method for the analysis of qualitative data in multi-disciplinary health research. BMC Medical Research Methodology 13, 117.

Gauld, R. 2010: Are elected health boards an effective mechanism for public participation in health service governance? Health Expectations 13, 369-78.

Goodman, C., Opwora, A., Kabare, M. and Molyneux, S. 2011: Health facility committees and facility management exploring the nature and depth of their roles in Coast Province, Kenya. BMC Health Service Research 11, 229.

Gregory, J. 2006: Conceptualising consumer engagement: a review of the literature. Working paper 1, Melbourne, Australia: Australian Institute of Health Policy Studies.

Gurung, G., Derrett, S., Gauld, R. and Hill, P. C. 2017: Why service users do not complain or have 'voice': a mixedmethods study from Nepal's rural primary health care system. BMC Health Services Research 17, 81 . 
Gurung, G., Derrett, S., Hill, P. C. and Gauld, R. 2015: Governance challenges in the Nepalese primary health care system: time to focus on greater community engagement? The International Journal of Health Planning and Management 31, 167-74.

Gurung, G. and Tuladhar, S. 2013: Fostering good governance at peripheral public health facilities: an experience from Nepal. Rural \& Remote Health 13, 2042.

Iwami, M. and Petchey, R. 2002: A CLAS act? Communitybased organizations, health service decentralization and primary care development in Peru. Journal of Public Health 24, 246-51.

Kapiriri, L., Norheim, O. F. and Heggenhougen, K. 2003: Public participation in health planning and priority setting at the district level in Uganda. Health Policy and Planning 18, 205-13.

Karkee, R. and Jha, N. 2010: Primary health care development: where is Nepal after 30 years of Alma Ata Declaration? Journal of Nepal Medical Association 49, 178-84.

Loewenson, R., Rusike, I. and Zulu, M. 2004: Assessing the impact of health centre committees on health system performance and health resource allocation. EQUINET discussion paper 18, Harare, Zimbabwe: EQUINET, TARSC.

Mahmud, S. 2004: Citizen participation in the health sector in rural Bangladesh: perceptions and reality. IDS Bulletin 35, 11-18.

McCoy, D. C., Hall, J. A. and Ridge, M. 2012: A systematic review of the literature for evidence on health facility committees in low- and middle-income countries. Health Policy and Planning 27, 449-66.

Meuwissen, L. E. 2002: Problems of cost recovery implementation in district health care: a case study from Niger. Health Policy and Planning 17, 304-13.

Molyneux, S., Atela, M., Angwenyi, V. and Goodman, C. 2012: Community accountability at peripheral health facilities: a review of the empirical literature and development of a conceptual framework. Health Policy and Planning 27, 541-54.

Patton, M. Q. 1990: Qualitative evaluation and research methods. Newbury Park, CA: SAGE Publications.

QSR International Pty Ltd. 2012: NVivo qualitative data analysis software, version 10.

Ramiro, L. S., Castillo, F. A., Tan-Torres, T., Torres, C. E., Tayag, J. G., Talampas, R. G. and Hawken, L. 2001: Community participation in local health boards in a decentralized setting: cases from the Philippines. Health Policy and Planning 16, 61.
Rifkin, S. B., Muller, F. and Bichmann, W. 1988: Primary health care: on measuring participation. Social Science \& Medicine 26, 931-40.

Sepehri, A. and Pettigrew, J. 1996: Primary health care, community participation and community-financing: experiences of two middle hill villages in Nepal. Health Policy and Planning 11, 93-100.

Serapioni, M. and Duxbury, N. 2014: Citizens' participation in the Italian health-care system: the experience of the Mixed Advisory Committees. Health Expectations 17, 488-99.

Simkhada, P., Regmi, P. R., Pant, P. R., Van Teijlingen, E. and Sathain, B. 2015: Stipulating citizen's fundamental right to healthcare: Inference from the constitution of Federal Republic of Nepal 2015. Nepal Journal of Epidemiology 5, 516.

Sohani, S. B. 2005: Health care access of the very poor in Kenya. Workshop Paper 11. Meeting the health related needs of the very poor, DFID Workshop, 14-15 February, London, England: Department for International Development.

Thomas, D., Sarker, A. H., Khondker, H., Ahmed, Z. and Hossain, M. 2003: Citizen participation and voice in the health sector in Bangladesh. Dhaka, Bangladesh: Department for International Development.

Tritter, J. Q. and McCallum, A. 2006: The snakes and ladders of user involvement: moving beyond Arnstein. Health Policy 76, 156-68.

United Nations Development Programme 2014: Nepal human development report 2014. Beyond geography: unlocking human potential, Kathmandu, Nepal: Government of Nepal, National Planning Commission and United Nation Development Programme.

Uzochukwu, B. S. C., Akpala, C. O. and Onwujekwe, O. E. 2004: How do health workers and community members perceive and practice community participation in the initiative programme in Nigeria?A case study of Oji River local government area. Social Science \& Medicine 59, 157-62.

Waweru, E., Opwora, A., Toda, M., Fegan, G., Edwards, T., Goodman, C. and Molyneux, S. 2013: Are health facility management committees in Kenya ready to implement financial management tasks: findings from a nationally representative survey. BMC Health Services Research 13, 404.

World Health Organization 1978: Primary health care: a joint report by the Director-General of the World Health Organization and the Executive Director the United Nations Children's Fund, Geneva, Switzerland: World Health Organization. 